\title{
Using Generative Learning Strategies for Assessment of Student Understanding in a Principles of Microeconomics Course
}

By

\author{
Mariya Burdina \& Katherine M. Sauer \\ Metropolitan State College of Denver
}

\section{DRAFT: PLEASE DO NOT QUOTE WITHOUT PERMISSION}

\begin{abstract}
$\underline{\text { Abstract }}$
According to the generative theory of learning, people understand new concepts by idiosyncratically relating them to prior experiences and prior stored information. In the case of economics, students' prior experiences can interfere with their correct understanding of the material. Although instructors may anticipate common student errors, unless the underlying incorrect mindset is directly addressed misperceptions may persist. This paper describes a practical strategy for using generative learning teaching techniques to help instructors assess whether students are correctly integrating new learning within the context of their prior experience. Insights from a piloting of the technique are discussed.
\end{abstract}

\section{Introduction}

It is not sufficient for instructors to have knowledge of the material they are teaching. To be most effective, they must also have knowledge of their learners. Learners do not enter the classroom as a blank slate. They bring with them an accumulation of years of experiences, stored knowledge, preconceptions and sometimes misconceptions. The new content that they are exposed to may integrate seamlessly into their schema, may be partially or incorrectly processed, or may be rejected entirely if it conflicts with what the learner already "knows" to be true. Instructors can learn to anticipate students' common thinking errors and halt misperceptions before they solidly take root. To this end, we provide an overview of common thinking errors related to content in a principles of microeconomics course. We propose that the generative learning integration strategy of creating analogies or metaphors can be used to assess whether the students are correctly thinking about a concept or if they are being held back by an incorrect mindset. Insights from piloting this technique are discussed.

\section{Common Thinking Errors}

According to The Generative Model of Mislearning and Recovery (Kourilsky 1993), in the economics discipline prior experiences and knowledge "... can divert the student toward representations and processes that are inconsistent or in direct conflict with correct understanding". For example, in lecture we can make a point of explaining scarcity does not mean rarity, a decrease in supply is a reduction in quantity at all prices, and the difference

\footnotetext{
* Corresponding author: Phone: 1-303-556-3037. E-mail: ksauer5@mscd.edu. Mailing Address: Metropolitan State College of Denver, Campus Box 77 - PO Box 173662, Denver, CO 80217.
} 
between positive and normative analysis. Despite our best efforts, some students continue to equate scarcity with rarity because in their mind that is what scarce really means. Students have a tendency to illustrate a decrease in supply by shifting it to the right because it then looks "lower". Students often hold on to preconceived opinions even in the face of a sound economic argument to the counter.

Examples of student "misthinking" fall into three categories: the linguistic mindset, the physical mindset, and the resistive mindset. The linguistic mindset is the tendency to identify with the everyday language usage of a word (e.g. scarcity vs rarity). Conflicts can occur either when the economic usage differs from the everyday usage or if the precision of the term matters (e.g. quantity demanded vs demand). The physical mindset derives from the students' physical experiences that cause misconceptions with regard to the understanding of graphical representations (e.g. shifting supply right to illustrate a decrease). The resistive mindset derives from the natural resistance to acknowledge a reality that is different from what the student believes "ought to be" the case (e.g. price ceilings aren't necessarily beneficial for consumers). These incorrect mindsets can impede students' understanding of economic concepts. Figure 1 presents some examples of economic concepts that may fall into each of the three incorrect mindsets. ${ }^{1}$

\section{Figure 1: Economic Examples of Incorrect Mindsets}

\begin{tabular}{|c|c|}
\hline Linguistic Mindset & Physical Mindset \\
\hline - scarcity vs rarity & - spending money has a cost but spending time doesn't \\
\hline - quantity demanded vs demand & - left shift in supply is a decrease \\
\hline - quantity supplied vs supply & - price ceiling is below equilibrium to bind, price floor is above to bind \\
\hline \multicolumn{2}{|l|}{ - inelastic elasticity } \\
\hline \multicolumn{2}{|l|}{ - public good vs public provision of a good } \\
\hline \multirow{3}{*}{$\begin{array}{l}\text { - zero economic profits vs not earning any money } \\
\text { - the “cost" in opportunity cost isn't just money cost }\end{array}$} & Resistive Mindset \\
\hline & - price controls are not always good for consumers (or producers) \\
\hline & - a monopoly isn't simply a bad thing \\
\hline - demand for labor vs wanting to have a job & - trade can benefit both parties involved \\
\hline - shift vs movement along & - sales tax on consumers or producers yields same outcome \\
\hline - unintended consequences vs negative externalities & - ceteris paribus \\
\hline - above vs increasing (on average-marginal graphs) & \\
\hline
\end{tabular}

To assess whether the students are correctly thinking about a concept or if they are being held back by an incorrect mindset, we propose the use of student-created analogies or metaphors. Analogies and metaphors are examples of the generative learning strategy of integration.

\section{Generative Learning Techniques}

Generative learning (Wittrock 1974) is by definition a very active process for the learner. The learner is relating the new information to information they already understand. They are creating their own connections between new concepts and stored information. Assessing the connections that the students have made can give insight to instructors.

\footnotetext{
${ }^{1}$ Your authors are interested in your own teaching experience. Have you encountered other concepts you think should be added to these lists? Please send an email to ksauer5@ mscd.edu if you are interested in contributing. We are always on the lookout for like-minded future co-authors.
} 
Sharp, Knowlton, and Weiss (2005) give an overview of three types of generative learning strategies as applied in an economics course. Strategies that promote organization involve the student imposing an organization on the content. This can take the form of an outline, summary, or concept map. Strategies that promote integration are those that assist students in making connections to their prior experience and knowledge. Paraphrasing and developing analogies or metaphors are two examples of integration strategies. Strategies that promote elaboration require the student to connect the new content with additional information. Examples include identifying real-world examples of the course content, predicting implications of policies, connecting course content to content from other disciplines, or hypothesizing causes for particular consequences.

\section{Using Analogies and Metaphors to Assess Understanding}

Analogies and metaphors are useful for making abstract concepts more concrete. People use them so often in everyday communication that they may not even be aware they are doing so. It is common to begin a statement with "Think of it as..." or "It is similar to ..." when explaining something that is unfamiliar to a client or friend. When students construct an analogy or metaphor they are relating new information to information they already understand. At a glance, an instructor can evaluate the students' analogies and gauge a class's understanding of a concept.

During fall semester 2010, this technique was piloted in a principles of microeconomics course. At the beginning of the semester, the instructor briefly reviewed the concept of analogies and metaphors. ${ }^{2}$ After a concept was taught in the usual manner, the instructor would offer an analogy or metaphor. The students were then tasked with coming up with their own. This assignment could be done as homework or in small groups. Whether discussed as a class or turned in individually, the instructor could readily see if the students were correctly integrating the new material with their prior knowledge or if they were making errors. Because the students' own language is used to construct analogies or metaphors, students could not simply regurgitate definitions and examples from class. The instructor could see if the concept was genuinely understood and could modify the lesson plan accordingly. Figure 2 presents an example.

\begin{tabular}{|c|c|}
\hline \multicolumn{2}{|c|}{ Instructor's Price Ceiling Analogy } \\
\hline \multicolumn{2}{|c|}{ Grocery stores often impose a limit on the number of sale items you may buy. } \\
\hline Analogy & Price Ceiling \\
\hline $\begin{array}{l}\text { - Store policy is to let you buy only a maximum number } \\
\text { of a particular item that is on sale. }\end{array}$ & $\begin{array}{l}\text { - Legally, a price ceiling is the maximum price that can be } \\
\text { charged. }\end{array}$ \\
\hline $\begin{array}{l}\text { - Some people would like to buy more than the limit, but } \\
\text { are not allowed to. }\end{array}$ & $\begin{array}{l}\text { - Some people would be willing to pay more in order to be } \\
\text { able to purchase the item, but are not allowed to. }\end{array}$ \\
\hline - Some transactions are prevented from taking place. & - Some transactions are prevented from taking place. \\
\hline \multicolumn{2}{|c|}{ Student-Generated Price Ceiling Analogies } \\
\hline $\begin{array}{l}\text { Correct } \\
\text { Many colleges have a maximum number of times you may } \\
\text { attempt a course. Some students would like to attempt the } \\
\text { same course more times, but are not allowed to. Some } \\
\text { transactions are prevented from taking place. }\end{array}$ & $\begin{array}{l}\text { Incorrect } \\
\text { Some airlines allow you to check one } 50 \text { pound bag free of } \\
\text { charge. Some people want to bring more baggage but don't } \\
\text { because they will have to pay for it. Some transactions are } \\
\text { prevented from taking place. }\end{array}$ \\
\hline
\end{tabular}

\footnotetext{
${ }^{2}$ Please see the Appendix for a review of analogies and metaphors.
} 
Several insights were gained from this pilot. Initially, some students had trouble with the basic concepts of analogies and metaphors. Although these devices are taught in K-12 curriculum, some students still struggled with the concept itself. A more thorough review of analogies and metaphors may be necessary for successfully implementing this technique in the future. Another notable trend was the tendency for students to try to find a metaphor quite similar to the one offered as an example by the instructor. This leads us to believe that those students may still be a little uncertain on the taught concept itself. That is, they don't fully understand it enough to devise their own analogy. Lastly, the question surfaced regarding how to best document the students' understanding. Whether this technique is best suited for an instructor's informal assessment "on the fly" during class or if it can be made more formal is an open question.

\section{Conclusion}

Because students bring prior experiences and knowledge to the classroom it is useful to be aware of situations where the understanding of new concepts may be impeded by students' prior schema. Generative learning techniques can be a way of tapping into the students' experience and knowledge and bridging it with the new content the instructor is presenting. The use of student-created analogies and metaphors can provide instructors with insight into the students' incorrect thinking and provide impetus for modifying the lesson plan. What remains to be determined is whether this technique also impacts student learning outcomes. Future work will include designing and implementing an experiment to see whether student-creation of analogies and metaphors actually aids in understanding concepts from the principles of microeconomics course.

\section{References}

Kourilsky, M. (1993) "Economic Education and a Generative Model of Mislearning and Recovery" The Journal of Economic Education 24(1): 23-33.

Sharp, D.C., DS. Knowlton, and R.E. Weiss (2005) "Applications of Generative Learning for the Survey of International Economics Course" The Journal of Economic Education 36(4): 345-357.

Wittrock, M.C. (1974) "Learning as a Generative Process” Educational Psychologist. 11(2): 87-95. Republished in original form in 2010 "Learning as a Generative Process" Educational Psychologist. 45(1): 40-45.

\section{Appendix: Review of Analogies and Metaphors}

An analogy is a similarity between like features of two things, on which a comparison may be made. Here are three examples:

Glove is to hand as paint is to wall.

Star is to galaxy as cell is to organism.

Fifth is to sixth as Halloween is to Thanksgiving.

A metaphor is an analogy between two objects or ideas; the analogy is conveyed by the use of a metaphorical word in place of some other word. 
Time flies.

The lawyer grilled the witness.

It is important to emphasize that analogies and metaphors will contain some of the same qualities or characteristics of the concept but will never be perfectly relatable. 